\title{
Interdisciplinarity: A Bridge Between Undergraduate Learners and Researchers
}

\author{
Adriana da Silva Jacinto, Eduardo Alves di Nizo, Marcelo Inácio da Silva, André Gomes \\ Vieira, Diego Germano, Thiago Luís Silva Fortunato, Emanuel Mineda Carneiro \\ Faculty of Technology Professor Jessen Vidal (Fatec-SJC) \\ Computer Science Department \\ São José dos Campos, SP, Brazil
}

\begin{abstract}
Education aims to promote development of skills and abilities in an individual and teaching - learning process is the main tool for this issue. However, for effective learning to occur, learners need to take an active attitude during this process, increasingly rare and a desirable situation in a society who seeks development and innovation. One way of tackling the problem is to modify teaching - learning paradigm, causing pupils become students and, therefore, researchers. This paper describes a case study related to an interdisciplinary proposal, applied to undergraduate learners of Computer Science, which instigated them to appropriate skills and abilities necessary to a researcher. Outcomes such as software and scientific papers authored by students indicate a promising way.
\end{abstract}

\section{Introduction}

Learning is the purpose of education. Moreover, learning must accompany the human being throughout his life. However, someone really learns when he assumes an active attitude concerning the taught lessons, i.e., a mere spectator learner becomes a student [1]. A student learns, retains, develops and enhances what was taught to him.

Autonomously, a student develops some of necessary qualities to a researcher, namely: critical thinking, dedication and discipline. To obtain innovation and development, a country needs to encourage the training of researchers, who contribute to advancement of knowledge [2]. This statement coincides with the Fricke's ideas [3], who says knowledge sustains wise decisions, and that is the key to troubleshooting.

However, obtaining knowledge and acquiring skills and abilities are difficult tasks, requiring effort and study, and most learners were not trained to become a student, but trained to try to get good grades and diplomas, making it a purpose and not a consequence from their studies [1]

To overcome that undesirable situation, an undergraduate learner must be encouraged to become a student and therefore a researcher. One way to get him to study is the adoption of inter, cross or multidisciplinary projects. Two or more subjects and a problem to be solved by learners have produced good results in process of teaching and learning, as verified in [4], [5], among others.

Analyzing those aspects, undergraduate learners of Database Technology course tried out a case study of an interdisciplinary approach. Under guidance of professors of subjects Learning Laboratory II, Programming Language I and Database, learners had to develop software that could be used in labor market. To fulfill that task, learners studied related concepts, found tools to model and implement a database, learned programming techniques, used innovation and wrote a scientific paper reporting the gained experiences.

This case study provided several significant results, including development of some skills necessary to a researcher and cooperation among students. Therefore, this paper has the following sections. Section 2 presents concepts which justify case study. Section 3 contains a summary of art state. Section 4 presents the adopted process for case study of interdisciplinary proposal. Section 5 reports experiments and results. Finally, Section 6 includes some conclusions.

\section{Background}

Learners are individuals enrolled in an educational institution and who attend classes. During course, when a learner applies and enhances his knowledge, he becomes a student [1]. At the end of the course, undergraduate students should be able to demonstrate training process was successful, through a project presentation [2].

Thus, an undergraduate learner must be encouraged to become a student and consequently a researcher, because the triad Education, Science and Technology has a strategic role in the economy of a nation [6]. In general, a researcher is the one who observes and investigates what is not yet known, being able to work on several projects. 
During acquiring process of knowledge, however, overcoming of fragmented view is essential in order to learners to become researchers [7]. On Computer Science, e.g., when a student builds models and implements a database without connecting it to any system, he will have a partial idea of usefulness of a database. This situation can generate misconceptions, students deduce that the various subjects are disconnected, and some are more important than others.

In addition, scientific and technological innovations happen on the fast way and undergraduate learners must have more than only theoretical contents: they need to assume an interactive and responsible attitude in society [5]. Based on this evidence, reshaping of the educational paradigm is necessary.

During the undergraduate course, one way to encourage the arising of researchers is to upgrade teaching model and to interconnect several taught contents through use of interdisciplinarity, once the literature recognizes its importance [8]. According to [7], an interdisciplinary approach allows integration of different areas, contributing to production of knowledge. Therefore, students must become responsible for their own learning, developing an active attitude in learning process. Such behavior is characterized by critical thinking, curiosity, inquiry and rigor in searching for information. In parallel, interdisciplinary practice mobilizes professors to face the contradictions presented by the real and concrete needs of students [7].

By practice of interdisciplinarity, reading habit, the seeking for more and better knowledge can be stimulated. According to [9], no unique definition for interdisciplinarity is possible, however that author provided some important insights.

The cited author [9] highlights that a set of theoretical principles supports the interdisciplinarity, whose mentors want to rescue the essence of knowledge's totality.

Gradually, use of interdisciplinarity improves the sense of interdependency and interaction among objects and ideas, making possible to understand several contexts, recovering the notion that all concepts and theories are interconnected themselves [9]. So, analyzing all promised benefits, this work considers interdisciplinarity as joining of two or more subjects to perform a set of tasks, called interdisciplinary project.

\section{Related Works}

One of main challenges of education is to develop study habits in learners. So, use of interdisciplinary projects has provided new ways to address this problem.

Through an interdisciplinary project called Differences, authors [4] report undergraduate students developed games, which address social issues such as communication with the deaf, honesty political and obesity. That project joined two disciplines: a) Programming Language; and b) Society, Technology and Innovation. From observations of students, authors tell positive outcomes: learning a programming language, development of various social games, improvement of critical and logical thinking, team spirit, mental agility and solidarity.

Talking about problems, others [10] performed an interdisciplinary experience using ill-structured problems. An ill-structured problem has no unique and exact solution, and can affect other scenarios, triggering other problems. Authors concluded use of interdisciplinarity is efficient and effective to instigate logical and critical thinking of students to promote common good.

Other authors [5] analyzed the perception of professors about interdisciplinarity on an Accounting course. Although interdisciplinarity is not explicitly adopted, those professors realize its importance for teaching practice, to improve education quality and training for students.

Occurrence of interdisciplinarity was also studied in Letters, Arts, Humanities, Social Sciences and other courses. In higher education, interdisciplinarity deserves to be reflected in all areas of university life and involves all stakeholders in process: managers, employees, professors and students [11], [12].

Some authors [13] conducted a research about interdisciplinarity. They concluded that successful collaboration requires effective communication. Then, it is necessary to have conscious effort, time and resources for the development of interpersonal relationships for this.

\section{Interdisciplinary proposal}

In a public higher educational institution, professors of Technology in Database course joined themselves in an interdisciplinary proposal, during the first semester of 2015. Enrolled subjects were: a) Programming Language, b) Database Modeling, and c) Development Laboratory. That is an evening course and learners are between twenty and fifty years old.

According to [7], each person's life stories are a great starting point for construction of interdisciplinary teaching. Thus, from their personal experiences and tastes, undergraduate learners were invited to develop software to be used on real world.

Since beginning of process, students were advised that software to be developed would need to have three characteristics: a) use of $\mathrm{C}$ programming language on implementation, b) implementation of graphical user interface; c) use of relational database, containing at least two related tables.

Such requirements are justified by the list of disciplines involved in proposal, providing to student to obtain better performance, since he would practice 
what has learned in classroom to develop his software. In different semesters, this graduation course offers the most widely used programming languages, and $\mathrm{C}$ proved to be adequate for second semester.

Under weekly supervision of Development Laboratory professor, and to systematize its execution, case study process was divided into stages. The steps have been named as: Ideas, Tools, Modeling, Screens, BD and Final. An explanation of each step is presented next.

- Ideas

In the first step, learners would have to conduct a field survey to identify or generate possible needs that would be supplied by their software. This step demanded time and patience from the part of students and professors, because learners had to design an abstract idea of their software without knowing a programming language or database management system that would use. Professors fit the definition of software scope and encourage flowering of creativity and perception of each learner.

- Tools

In the second step, learners would have to think over some characteristics, such as whether software would be for web use, if there would be interaction between two different programming languages, what management system database to be used, among others. Professors gave students freedom to choose what they would like to work on.

- Modeling

In the third step, learner would do a survey requirement that the software should accomplish. From this, the learner could define entities and their attributes, generating entity relationship model for database.

\section{- Screens}

During the fourth step, student would have to present a prototype of software screens. In market, software that employs graphical user interface (GUI) is more attractive and interesting than others.

- Database

In the fifth step, student's challenge was to make connection between software and database, making possible to create, read, update, and delete on database.

- Final

In the last step, student should present the operating software and a scientific paper about development of his software. Though the paper will be not submitted to any event, its writing allows that the student organize his thinking.
During all steps, attitude of professors has been exercising an active and creative expects, offering alternatives for students believed they could complete the project and acquire meaningful learning.

\section{Case study experiments}

From each step of case study, byproducts arose such as skills, abilities, new ideas and solutions. Some of those results are shown next.

\section{- Ideas}

Every learner made a presentation about what would be his software and what need would be attended. Table 1 shows some of displayed items.

Table 1. Ideas software

\begin{tabular}{|c|c|c|}
\hline Name & Problem & Goal \\
\hline $\begin{array}{l}\text { Projeto } \\
\text { Dentista }\end{array}$ & $\begin{array}{c}\text { Small dental offices do } \\
\text { not have a } \\
\text { computerized control } \\
\text { of patient information. }\end{array}$ & $\begin{array}{c}\text { To develop a } \\
\text { software which } \\
\text { allows storage } \\
\text { and access to } \\
\text { patient } \\
\text { information. }\end{array}$ \\
\hline TodoList & $\begin{array}{l}\text { People forget to } \\
\text { perform simple } \\
\text { activities during day } \\
\text { and thereby impact } \\
\text { implementation of } \\
\text { major tasks and } \\
\text { activities. }\end{array}$ & $\begin{array}{l}\text { To deliver a } \\
\text { software to } \\
\text { manage daily } \\
\text { tasks via web } \\
\text { platform. }\end{array}$ \\
\hline StockPocket & $\begin{array}{l}\text { Multifunctional } \\
\text { systems make difficult } \\
\text { to control products. }\end{array}$ & $\begin{array}{c}\text { To develop a } \\
\text { simple and } \\
\text { objective control } \\
\text { system product. }\end{array}$ \\
\hline $\begin{array}{l}\text { Software de } \\
\text { Repetição } \\
\text { Espaçada }\end{array}$ & $\begin{array}{l}\text { When people learn a } \\
\text { new language often is } \\
\text { difficult to keep words } \\
\text { in mind. }\end{array}$ & $\begin{array}{l}\text { To develop a web } \\
\text { application which } \\
\text { assists learners to } \\
\text { review contents }\end{array}$ \\
\hline Troca Fácil & $\begin{array}{l}\text { To perform preventive } \\
\text { maintenance of a car, } \\
\text { technicians must search } \\
\text { specifications referring } \\
\text { to oil filter, air filters, } \\
\text { fuel filters and } \\
\text { lubricants. Those tasks } \\
\text { take time. }\end{array}$ & $\begin{array}{l}\text { To develop } \\
\text { software to help } \\
\text { technicians. }\end{array}$ \\
\hline
\end{tabular}

Table 1 presents five ideas which treat real problems. At this step, learners showed up insecure about completion of the projects. Professors defined scope of every software, guiding learners that the time for development was only one semester.

- Tools

Defined a focus for development, learners had to search and select tools which would be used in project performing. In general, choice fell on six groups of 
tools: a) C programming language [14], interface development environment Code Blocks, creation environment Glade GTK graphical interface [15]; b) Interaction between the languages $\mathrm{C} \#$ and $\mathrm{C}$ development environments Code Blocks and Visual Studio c) for Web development languages such as HTML, CSS and JavaScript; d) AngularJS [16] and JQuery framework; e) use of CGI (Common Gateway Interface) [17]; f) MySQL [18] was chosen as database manager system (DBMS) for all software.

On 1972, Dennis Ritchie developed C programming language at Bell Labs [14]. Table 2 presents how much $\mathrm{C}$ programming language is popular, among others.

Table 2. Ranking of programming language

\begin{tabular}{|c|c|c|c|}
\hline July 2017 & July 2016 & $\begin{array}{c}\text { Programming } \\
\text { language }\end{array}$ & $\begin{array}{c}\text { Ratings } \\
(\%)\end{array}$ \\
\hline 1 & 1 & Java & 13.774 \\
\hline 2 & 2 & $\mathrm{C}$ & 7.321 \\
\hline 3 & 3 & $\mathrm{C}++$ & 5.576 \\
\hline 4 & 4 & Python & 3.543 \\
\hline 5 & 5 & $\mathrm{C \#}$ & 3.518 \\
\hline 6 & 6 & PHP & 3.093 \\
\hline 7 & 8 & $\begin{array}{c}\text { Visual } \\
\text { Basic.NET } \\
\end{array}$ & 3.050 \\
\hline 8 & 7 & JavaScript & 2.606 \\
\hline 9 & 12 & $\begin{array}{c}\text { Delphi/Object } \\
\text { Pascal }\end{array}$ & 2.490 \\
\hline 10 & 55 & Go & 2.363 \\
\hline 11 & 9 & Perl & 2.334 \\
\hline 12 & 14 & Swift & 2.253 \\
\hline 13 & 11 & Ruby & 2.249 \\
\hline 14 & 10 & $\begin{array}{l}\text { Assembly } \\
\text { language }\end{array}$ & 2.240 \\
\hline 15 & 17 & $\mathrm{R}$ & 2.105 \\
\hline 16 & 13 & Visual Basic & 2.096 \\
\hline 17 & 16 & MATLAB & 2.009 \\
\hline 18 & 15 & Object-C & 1.896 \\
\hline 19 & 21 & Scratch & 1.813 \\
\hline 20 & 18 & PL/SQL & 1.545 \\
\hline
\end{tabular}

The above Table is adapted from [19].

Table 2 shows the top twenty ratings of programming language, and $\mathrm{C}$ is the second most popular in July 2017. According to [19], in March 2015, C programming language occupied the first position on ranking. The index shown in Table 2 is an indicator of the popularity of programming languages, which is updated once a month. Popular search engines such as Google, Bing, Yahoo!, Wikipedia, Amazon, YouTube and Baidu are used to calculate the ratings, which are based on the number of skilled engineers world-wide, courses and third party vendors [19].

Using C programming language, learners can write a code of program for computer. To write, compile and run this code, learner should use an interface development environment (IDE). So, Code Blocks is a valid alternative of using, because it is open source, cross platform, free C, C++ and Fortran IDE [20].

As one of software's requirements to be accomplished is the presence of graphical user interface, Glade GTK showed itself as an option. It is a tool to enable development of user interfaces for the GTK+ toolkit and the GNOME desktop environment. The Glade interface is saved as XML file and, by using GtkBuilder, this file can be used in C programming language, among others [15].

Some learners chose to integrate web pages and C program. In this case, the graphical user interface was made by using of JavaScript, HTML and CSS. To interconnect web pages and $\mathrm{C}$ program, learners used CGI, AngularJS and JQuery framework. CGI allows the computer to generate web pages instantly at the user's request [17].

MySQL delivers a robust SQL (Structured Query Language) database server, and it is a trademark of Oracle Corporation [18]. It has several interesting features, such as [18]: written in $\mathrm{C}$ and $\mathrm{C}++$; works on many different platforms; provides the server as a separate program for use in a client/server networked environment; password security by encryption of all password traffic; support for large databases; and so on.

Every learner chose to use what tools they wanted. Professors just demanded $\mathrm{C}$ programming language should be included.

\section{- Modeling}

Every student-built entity relationship model of their software. That database should contain at least two related tables. From this step, each student began to study and to research items by on his own. Figure 1 shows logical model relating to TodoList database.

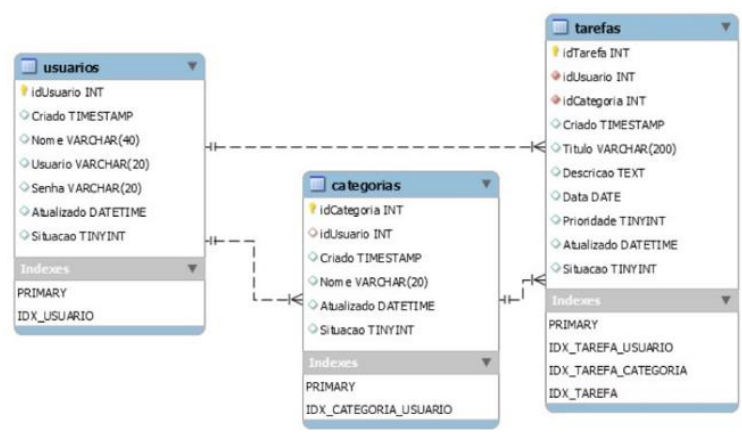

Figure 1. Logical model for TodoList

Figure 1 shows three tables named as usuarios, categorias and tarefas. Every table has attributes whose values are data to be stored. For example, from entity user, represented by table usuarios, seven data will be saved on database. Also, the relationships among the tables appears in Figure 1. 
Building this model shown in Figure 1, student applied concepts of primary and foreign keys. Also, the type of every attribute appears. Each model was evaluated and corrected by Database Modeling professor. If there were any problems, student should work around.

\section{- Screens}

Development Laboratory professor showed some examples of screens, using Glade GTK and Allegro. From that, students built their prototype screens. An example is illustrated in Figure 2.

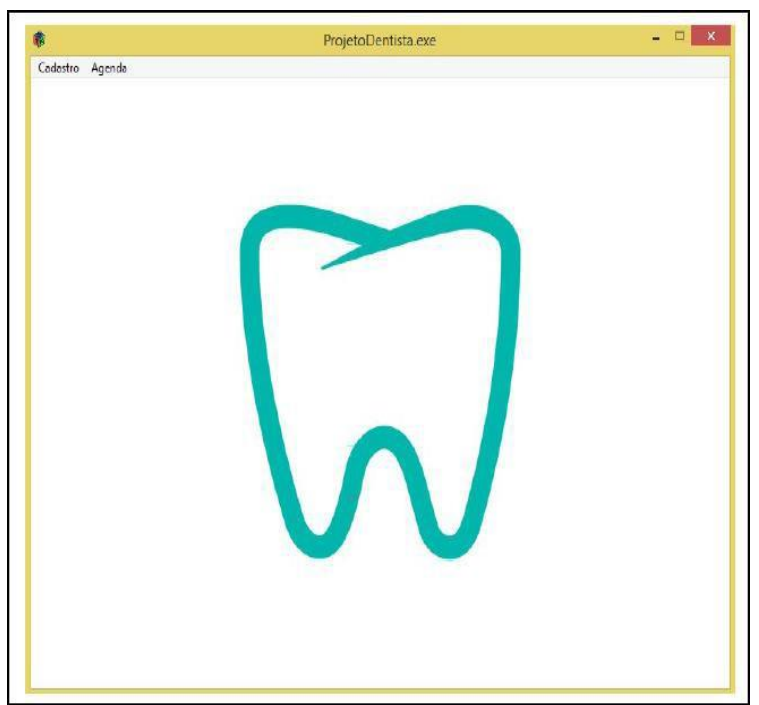

Figure 2. GUI of Projeto Dentista

Figure 2 illustrates initial screen of Projeto Dentista, which has a menu for patient's registration and scheduling appointments. When modeling screen prototype, student had a more realistic notion of what would be his software and what could be developed. In this step, professors asked an interaction between screen and user, even partial.

\section{- $\mathrm{BD}$}

After practical classes on SQL and basic database operations, students created their database and connected it to the software. Using $\mathrm{C}$ programming language, a student carried out the necessary code to access a MySQL database, running SQL commands. Figure 3 shows an excerpt of code related to those operations. As shown in Figure 3, listarCodPaciente function belongs to Projeto Dentista and executes a reading operation in the database. This function will return a list containing patient codes.

Also, Troca Fácil software executes queries operation to fill the fields motor power, year, air filter, oil filter, fuel filters and lubricants. According to selected car model, a list of items related to maintenance appears. Figure 4 exhibits a screen of Troca Facil software that illustrates the recovery of data on database.

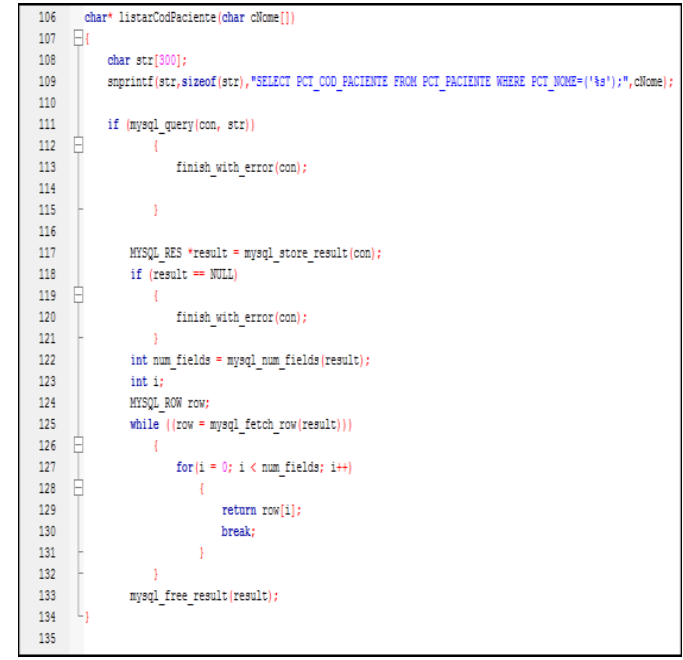

Figure 3. Sample of code

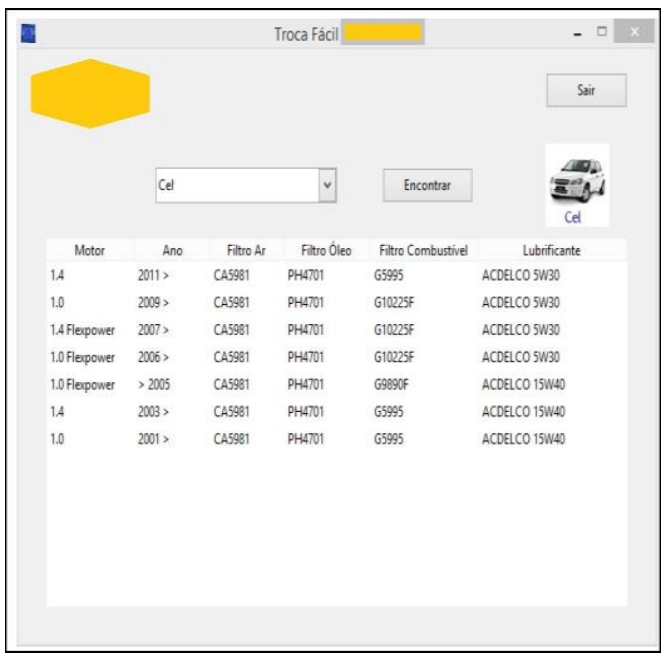

Figure 4. Recovery data on Troca Fácil

Figure 4 shows a screen where it is possible to visualize the image of car and all items of preventive maintenance. Looking at this screen, a mechanical technician can find the items for execution a correct maintenance on a car.

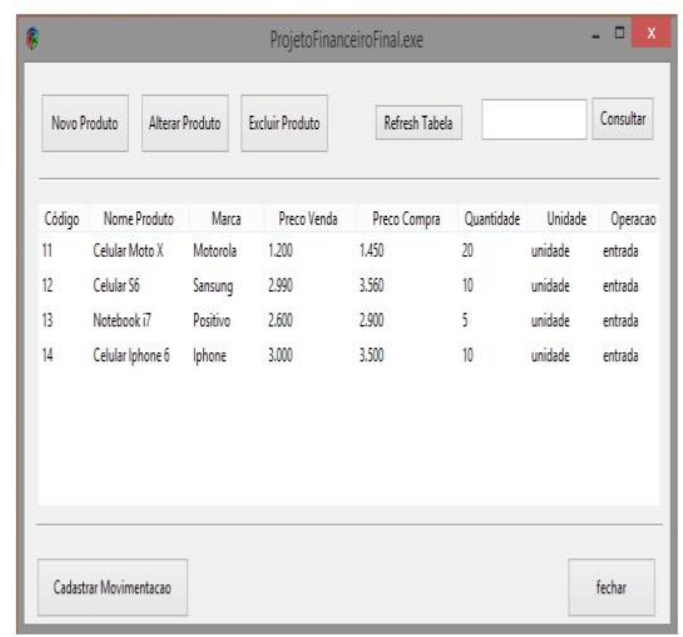

Figure 5. CRUD for StockPocket 
Another example of queries operations on database is given in Figure 5. It shows results of CRUD on database. Figure 5 shows that from same screen of StockPocket software it is possible to accomplish CRUD (Create, Read, Update, Delete) operations. The buttons Novo Produto, Alterar Produto, Excluir Produto and Consultar make possible these operations.

Button Novo Produto allows to create a new product on database, storing all its data as code, name, trademark, purchase and sale prices, available quantity, unity and operation. The unity refers to which unity of measurement is used to count that product, e.g., inch, $\mathrm{cm}, \mathrm{km}$ and so on.

To read data about a product, the user needs to provide its code and to click on button Consultar. From this, all data related to that product will be shown on the screen.

Whether the user wants to update data of any product, he need to click on button Alterar Produto. All data can be modified except the code of product because it is a unique identifier.

To delete a product of database, the user should click on button Excluir Produto. The execution of this operation means that the product will not be acquired by the company again.

On this step, all software is almost finished. The students adjust some details and professors provide the last concepts. Both professor and student feel that the journey was valid.

- Final

On the final step, students could think over their learning path, from beginning of semester to the delivery of software.

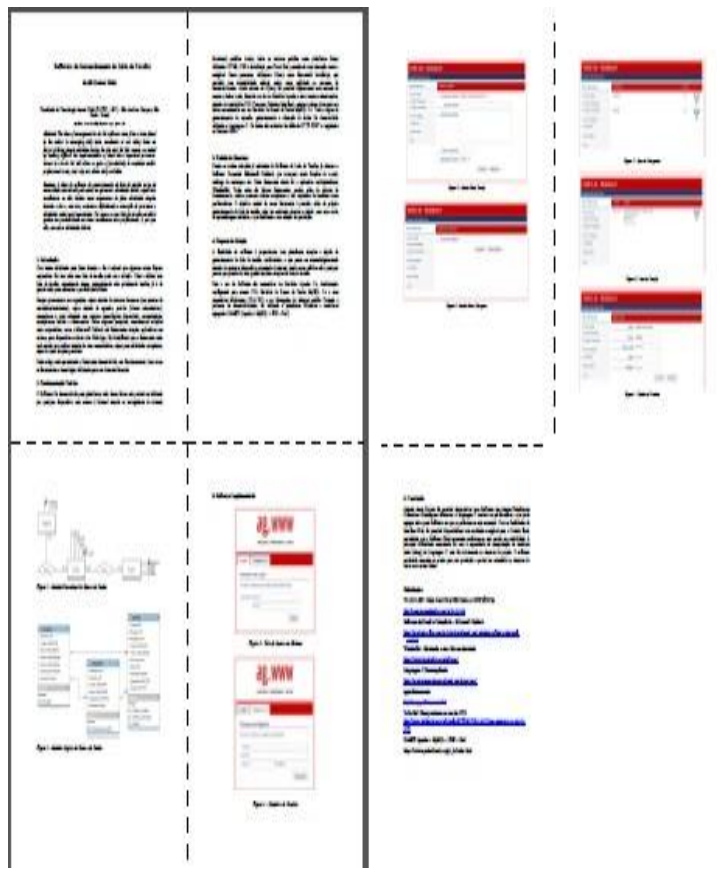

Figure 6. Sample of paper
In this point, the writing of a scientific paper is recommended. Figure 6 illustrates a paper written by a student.

To direct writing of papers, Development Laboratory professor made available a template, based on [2], containing sections that should exist in an article, namely: Abstract, Introduction, Theoretical Framework, Literature Review, Proposed Solution, Description of the Developed Software and Conclusion.

In Abstract section, students should provide a concise description about the treated subject. The professor advised them that a good abstract declares the problem and its causes. In addition, the students were aware that an abstract should indicate the found solution or contribution for solving the problem, and its implications as well. Some abstracts, titles and number of pages of students's papers are highlighted next

Title: Consultório Odontológico

Abstract:This article describes the development of Laboratory II material design. The encountered problem was the lack of a computerized system for dental offices that had no control of patient information. The solution was to develop an application that stores and manipulates patient's information. Pages: 6

Title: Software de Gerenciamento de Lista de Tarefas

Abstract: The idea of management to-do list software came from an issue found by the author in managing daily tasks, academics or not. Many times, we forgot of doing simple activities during the day and, for this reason, we ended up making difficult the implementation of much more important processes. Access to a to-do list will allow us gains of productivity in academic and/or professional areas, and, why not, others daily activities.

Pages: 7

Title: StockPocket - Sistema de Controle de Estoque de produtos ou peças

Abstract: This article describes the creation of a simple and objective system of inventory control. There are many multifunctional systems hindering usability and jeopardizing the control of the products, the objective of this software is to walk the other way, with something basic and fully meet the functionality to which they relate. With a quick solution to this problem, the system seeks to achieve intuitive features like filters to streamline a seek registration, modification 
and deletion of products and their respective drives.

Pages: 7

Title: Software de Repetição Espaçada

Abstract: The idea of spaced repetition software came from an issue found by the author in an English language learning journey. The observed problem was forgetting words. Studying more about it, the author found what researchers call Forgetting Curve which is basically the relationship between forgetting and time, the main idea is the person reviews the contents which he wants to memorize periodically, therefore making the time of forgetting increases exponentially.

Pages: 9

\section{Title: Troca Fácil XX}

Abstract: This article describes the solution to an everyday problem in the situation where the machine shop technician to carry out consultation with oil filters, air filters, fuel filters and lubricants for motor vehicles the automaker XX, do not waste time doing manual queries in paper catalogs, thus saving time and avoiding problems of carrying out the exchange for any incorrect piece. For the Troca Fácil XX System will assist in this step. Pages:11

The presented abstracts reveal a little more about the writing style of students, their ideas, observed problems and their designed softwares. Though improvements and revisions are necessary, the students could write their first papers.

In Introduction section, the professor said to her students to try answer the following questions:

a) Why this issue is interesting?

b) What is the main involved problem on?

c) Is there some previous solution for the problem?

d) What are proposal of solution and objectives?

e) What is the focus of the work?

f) What contents are going to be presented by next sections of the article?

In Theoretical Framework section, the students should describe the theory about the subject and which matters they needed to study for implementation of sotware. In addition, Literature Review section should present related works, i.e., similar softwares.

Proposed Solution section should explain all details of implementation and design of software. In Description of the Developed Software section, the students should present a brief tutorial of their software.

Among all sections of every article, conclusion was the most important because it described what student learned from the project and encountered difficulties during development. From conclusion, professors could extract materials and ideas to evaluate and improve proposal of interdisciplinary project. Some excepts of students' s conclusions are highlighted next.

"At the beginning of development, to learn in $C$ programming language was difficult due to its syntax and structured programming mode (...). The greatest difficulty was to connect and manipulate both $C$ programming language and Glade Gtk graphical interface, due to the lack of materials available for study in Portuguese. This was solved with the help of the teacher who provided contents and tips for creating and interacting Glade components with the $C$ language programming. In the future, I intend to continue the project making it more complete in relation to the management of dental offices."

Student - author of Projeto Dentista.

"Working in this project it was possible to develop a software that integrates different platforms and paradigms. The $C$ programming language has shown good performance (...). The use of web interface provided a friendly environment for end user. The main difficulty was with the ability to manipulate text variables (string) on $C$ programming language. This issue was solved during the project."

Student - author of TodoList.

"During the development of this project, new learning, new techniques for problem solving, (...) and so on were acquired. First, the encountered difficulties were to connect graphical interface Glade GTK, database $M y S Q L$ and to understand how pointers work. Understanding how pointer work helped a lot in the development of the program, as well as learning about the communication of widgets. The system can be concluded due to guidance of teachers, self-studies, and knowledge acquired from several subjects of the course (...)".

Student - author of StockPocket.

"The main difficulty was the manipulation of texts on $\mathrm{C}$ programming language, which was solved with research and with the absorbed content during the lessons (...)."

Student - author of Software de Repetição Espaçada.

"It was possible to learn a new programming language, new problem-solving techniques, a new logical thinking format. Besides, we understood 
that dedication makes learning flows. During development, there were many difficulties, such as creation of interface screens, communication with the database and interconnection among the languages. All problems were solved with class follow-up, teachers' orientation, studies and research(...). "

Student - author of Troca-Fácil.

The act of writing a conclusion led students to thinking over all their work, including successes and challenges. The students could review their learning path and observe their progress.

\section{Conclusion}

This paper presented an interdisciplinary proposal applied into a case study. Undergraduate students developed inherent skills and abilities to researchers. From this case study, positive outcomes were collected.

Students took an active attitude towards teachinglearning process, their self-esteem increased, they realized they can design and develop something of merit. Besides, they realized connection between course subjects and importance of each one.

Students mentioned apprenticeship of new technologies and languages as positive points. Also, they cited scientific writing as a discovery for them. Others said to learn something that will have immediate application in a software designed and developed by themselves is much more exciting.

Another interesting point was students said they felt to improve English learning is needed because many manuals and materials of new technologies are written in that language. Also, to write abstract of paper, students had to consult English professor to remedy doubts. Indirectly, subjects related to communication and expression have benefited from realization of interdisciplinary project.

Students stressed that learned to seek solutions for problems, researching unknown subjects and to develop a new format of thinking and logic. In addition, students reported teaching-learning process flows more naturally, when dedication and work exist.

Using an interdisciplinary approach, teaching paradigms can be reviewed, contributing to emerging of new researchers among many students. That initiative will provide the flourishing of more innovation and development in country.

Professors concluded that to join efforts produces better outcomes, and because that, they intend to extend the experience even more.

\section{References}

[1] P. Piazzi, Aprendendo inteligência: manual de instruções do cérebro para alunos em geral, 2nd ed. São Paulo: Aleph, 2008.
[2] Raul Sidnei Wazlawick, Metodologia de Pesquisa para Ciência da Computação, 2nd ed. Rio de Janeiro: Elsevier, 2014.

[3] M. Frické, "The knowledge pyramid: a critique of the DIKW hierarchy,” J. Inf. Sci., vol. 35, no. 2, pp. 131-142, 2009.

[4] A. Da Silva Jacinto, T. M. Almeri, E. Lamas, L.A. V. Dias, and A. M. Da Cunha, "Computer science and interdisciplinarity: A case study on an undergraduate program," Proc. 2013 10th Int. Conf. Inf. Technol. New Gener. ITNG 2013, pp. 289-293, 2013.

[5] I. R. Peleias, J. de F. Mendonça, V. G. Slomski, and I. C. A. Fazenda, "Interdisciplinaridade no ensino superior: análise da percepção de professores de controladoria em cursos de ciências contábeis na cidade de São Paulo," Avaliação, ..., vol. 16, no. 3, pp. 499-532, 2011.

[6] A. M. N. Machado and L. Bianchetti, "(Des)fetichização do produtivismo acadêmico: desafios para o trabalhadorpesquisador," Rev. Adm. Empres., vol. 51, no. 3, pp. 244 254, 2011.

[7] C. M. Haas, "Interdisciplinaridade: Uma Nova Atitude Docente," Olhar Profr., vol. 10, no. 1, pp. 179-193, 2009.

[8] F. Hacklin and M. W. Wallin, "Convergence and interdisciplinarity in innovation management: a review, critique, and future directions," Serv. Ind. J., vol. 33, no. 78, pp. 774-788, May 2013.

[9] J. da S. Thiesen, "A interdisciplinaridade como um movimento articulador no processo ensino- aprendizagem," Rev. Bras. Educ., vol. 13, no. 39, pp. 545-554, Dec. 2008.

[10] A. da S. Jacinto, T. M. Almeri, and J. M. P. de Oliveira, "Aprendizagem baseada em problemas mal-estruturados: Programação e Cidadania," in Anais do do XXII SBIE XVII WIE, 2011, pp. 1197-1206.

[11] J. D. A. Lopes, "Práticas Interdisciplinares No Ensino Superior: Dilemas E Estudos Nas Áreas De Letras E Artes Interdisciplinary Practices in Higher Education: Dilemmas," no. 1, pp. 77-86.

[12] E. A. Araújo and J. de Lopes, "As práticas Interdisciplinaridades: Análise dos obstáculos didáticos e epistemológicos das áreas de Ciências Humanas e Ciências Sociais Aplicadas," Rev. Educ. PUC-Campinas, vol. 15, pp. 89-98, 2003

[13] M. Marzano, D. N. Carss, and S. Bell, "Working to Make Interdisciplinarity Work: Investing in Communication and Interpersonal Relationships,” J. Agric. Econ., vol. 57, no. 2, pp. 185-197, Jul. 2006.

[14] A. Backes, Linguagem C: Completa e Descomplicada. Rio de Janeiro: Elsevier, 2013.

[15] Glade -A User Interface Designer, The Glade Project, 2014. [Online]. Available. https://glade.gnome.org, (Access date: 10 Apr, 2015). 
[16] Build Apps with AngularJS, Chrome, [Online]. Available: https://developer.chrome.com/apps/angular_fra mework\#_blank, (Access date: 12 Apr, 2015).

[17] S. Gundavaram, CGI Programming on the World Wide Web, 1st ed. O’Reilly Open Books Project., 1996.

[18] MySQL, Oracle, 2017. [Online]. Available: https://www.mysql.com/, (Access date: 05 May, 2015).

[19] TIOBE - The Software Quality Company, TIOBE software BV, 2017. [Online]. Available: https://www.tiobe.com/tiobe-index/, (Access date: $12 \mathrm{Jul}$, 2017).

[20] Code: Blocks - The IDE with all the features you need, having a consistent look, feel and operation across platforms, Code: Blocks, 2017. [Online]. Available: http://www.codeblocks.org/, (Access date: 12 Jul, 2017). 